\title{
Chinese student mobility, local engagement and transformation of Chinese communities in England: An empirical study
}

\author{
Bin Wu
}

\author{
School of Contemporary Chinese Studies, University of Nottingham \\ (This is a chapter of Entrepreneurship and Talent Management, edited by Huiyao Wang and Yipeng \\ Liu, published by Edward Elgar 2016)
}

\begin{abstract}
Unprecedented growth and circulation of Chinese international students cannot be fully understood unless the roles of host societies including diaspora Chinese communities are taken into account. This chapter draws attention to a phenomenon of local engagement, a process of interconnections and interactions between Chinese students and local communities, leading to a co-development of both Chinese students and diaspora Chinese communities in host countries. The links and impacts of Chinese student mobility in local communities can be seen from the landscape change of Chinese communities in England since the $21^{\text {st }}$ century. Accordingly, this chapter aims to address two questions: Why is local engagement important for Chinese student development in destinations? What are the impacts on the development and transformation of diaspora Chinese communities? Empirical evidence are based upon the combination of official data sources (UK Census and higher education statistics)analysis and a questionnaire survey conducted on Nottingham's Chinese community. Policy implications for global talent training and co-development with diaspora Chinese communities are discussed.
\end{abstract}

Key Words: Chinese student mobility, diaspora Chinese communities, local engagement, codevelopment, England

\section{Introduction}

Since the beginning of the 21st century, we have witnessed a rapid growth of international students in not only university campuses but also university cities or towns in the UK and other countries.With regard to the multiple impacts of international student mobility (ISM)on host countries, the debate has so far concentrated on the nature of ISM: migration or circulation (de Wit et al, 2008; King and Raghuram, 2013; Raghuram, 2013); the demand and/or supply side(s)(Findlay, 2011) and the transnational ties and impact on student migration decision making (Geddie, 2013). Nonetheless, there is an increasing emphasis on the multiple roles of international students inlocal communities such as students, migrants, family members (Robertson, 2011; King and Raghuram, 2013). This chapter goes further and draws attention to the roles of diasporacommunities in 
attracting, hosting and facilitating international student mobility and integration in local communities.

In relation to the theme of this chapter, the recent release of the UK Census indicates a growth of minority ethnic population in England and Wales: from 5.9\% in 1991 to $8.7 \%$ in 2001 and a further subsequent acceleration of growth over the following decade to $14.0 \%$ in 2011 . Furthermore, the growth of minority ethnic population is uneven in terms of geographic distribution. While many factors may reshape the ethnic landscape, it is reasonable to ask two questions: is there any impact from ISM;and, if so, how can we observe and analyse it?

With a focus on the link between international students and diaspora communities in the UK, perhaps, Chinese students offer a unique case to study. This is due to three reasons. Firstly, Chinese students from the People's Republic of China (PRC) form a leading group in the global higher education market while the UK is one of most attractive destinations for Chinese students. Secondly, Chinese international students are not limited to students from PRC, but also include other major sources of international student suppliers such as Hong Kong, Singapore and Malaysia - most of them are Chinese in term of ethnic background. Thirdly, the Chinese form one of the fastest growing ethnic groups in the UK: its share of the total national population rose from $0.4 \%$ in 2001 to $0.7 \%$ in 2011 (ONS, 2012).

With respect to the relationship between Chinese student mobility and diaspora Chinese communities in host countries, two interconnected questions arise here: Why is local engagement, referring to an process of interconnections and interactions between international students and local groups in the wider community outside of universities, important for Chinese students to develop their local knowledge, work experience, and plan of their future career and migration decision? What are the impacts on Chinese student mobility on the development and transformation of diaspora Chinese communities?

The above questions will be addressed by a combination of official data analysis across England and a questionnaire survey on Nottingham's Chinese community. The former involves two official data sources, the UK Census (2001 and 2011 respectively) from the Office of National Statistics (ONS) and the international student dataset from the Higher Education Statistical Agency (HESA), in order to reveal the landscape changes of Chinese communities and its relationship with Chinese student mobility. The latter was conducted in the summer of 2013 in order to examine local engagement and impact on the co-development of both Chinese students and diaspora Chinese communities.

The arguments will be organised as follows. The next section is a literature review to identify the research gaps in local communities, ethnic factors and student engagement in destinations. It is followed by conceptual framework, research hypotheses, data sources and analysis methods. Three sections are arranged afterwards to present the results of data analysis, including: evolution of government policy adjustments for Chinese student mobility and overseas Chinese communities since the 1980s; the correlation of the growth and distribution between Chinese students and diaspora Chinese population across England; and highlights of research findings from Nottingham Chinese community survey. This chapter ends with discussion and conclusion. 


\section{Literature Review: Dimension and research gaps of international student mobility (ISM)}

With respect to the movement of international students world-wide, the term ISM is often used as a combination of international students mobility and migration because it is not easy to distinguish them clearly. Involving nearly five million young people and their families' interests worldwide, unsurprisingly, the phenomenon of international student movement cannot be seen only as one type of movement. In this chapter we use the term international student mobility (ISM) to refer to different types of international students' movement across national borders for different purposes (King and Raghuram, 2013).

From the perspective of consequences on host countries, furthermore, ISM can be divided into two types--circulation and migration. The former refers to the process of returning to the sending country once the degree or training course is completed while the latter denotes the process of settling down in the host country to take up any job opportunities there. The term "student choice" is used in this chapter referring to a process of communication and interaction between international students and local communities including their own diaspora communities for information and job (career) opportunities, leading to a decision making between staying or returning at the end of their study period. For the purpose of this chapter, we ignore the other possibility such as moves to countries other than the sending and host countries.

In relation to student choice, it is increasingly recognised that international students may play multiple roles during the period of their study such as that of a family member, worker and student (Neilson, 2009; Geddie, 2013; Mosneaga and Winther, 2013). Depending upon the labour market situation and the political atmosphere in the host country, furthermore, student choice is largely influenced or determined by migration policies which may vary greatly across host countries, leading to policy debates about the global competition to attract international students (Hawthorne, 2012; Merrick, 2013; Sovic and Blythman, 2013; BIS, 2013). Two questions emerge regarding the multiple roles and choices of international students. Firstly, to what extent can international students be treated as a heterogeneous group in terms of their choices between circulation and migration? And what are the key factors influencing their choices and decision making? Linked to each other, the first question requires more empirical studies while the second relates to a large body of literature, which can be distinguished by different angles of observation and levels of analysis, including individual rational choice; the transnational network influence, and the world-system perspective.

According to neo-classical thinking, international student mobility and choice between staying and returning can be analysed and approached using a push-pull model which involves one or many factors, such as human capital, career development, affordability and social mobility, global market competition, quality of HE provision and services, and government policies from either or both sending or host countries' perspectives (Wiers-Jenssen, 2008; Shen, 2009; Xiang and Shen, 2009; Findlay, 2011). Despite different names and disciplinary backgrounds, essentially, scholars in this camp share more or less a common belief that ISM is a process of rational choice by individuals as bearers of human capital (Raghuram, 2013). One question arises from this approach, however, is whether all international students from the same country can be viewed as a homogeneous group in terms of their motivations for studying abroad before their migration and their decisionto stay or 
return after the completion of their university studies. So is their experience in living and working in the host country influences from the local communities which can hardly be assumed the same.

Disagreeing with the separation between sending and host countries, the transnationalism approach emphasises on the connections between places (Guarnizo, 2002; Gargano, 2009) at various levels from transnational and national to local levels (Collins, 2009; Brickell and Datta, 2011). Instead of individual choice, furthermore, the role of transnational social ties and in particular family decision making is highlighted (Waters, 2006; Geddie, 2013). In particular, increased emphasis is given to the inter-relations between human, economic, social and cultural capitals with education including international higher education (Bourdieu, 1986). While transnationalism offers an insight to the variety of student choice and influence of social factors across national boundaries, the influence of student learning from their experiences abroad and also the independence of their choice may be underestimated. In addition to social interactions between individual students and their social networks including their families, friends and classmates across national and international boundaries, their communication and social practices with local communities should not be ignored .

Not limited to individual or group choice, ISM can be viewed as part of the broad process of globalisation which has enhanced or reshaped the global capitalistic system. In this regard, the NeoMarxism approach sheds new light on ISM and inequalities between sending and host countries (Kell and Vogl, 2008a and 2008b; Raghuram, 2013). The politico-economic perspective on the inequality behind ISM can be analysed using different terms or angles such as brain-drain (Bhagwati, 1976), brain gain and circulation (Saxenian, 2005), "pedagogic soft power" (Figueroa, 2010), historiography of "modernisation", "Americanization" and "development" (Kramer, 2009: 776). From the perspective of global political economics, the world-system approach offers critical thinking and valuable insights into the nature of ISM and implications for both sending and hosting communities at the macro level. However, a research gap remains throughout this approach, which is that student choice at the micro-level cannot be fully understood unless the dimension of communication and interaction between international students and local communities is added.

To conclude, the different approaches described above have both advantages and disadvantages in terms of understanding and interpreting the complexities of ISM and the student's choice between circulation and migration. A common gap seen in all three perspectives lies in the roles of local communities in terms of facilitating and supporting the social lives of international students in the host country. Accordingly, this paper will fill this research gap by adding a new dimension--local communities - and a new factor-- the diaspora community to the choice of international students.

\section{Research framework, data sources and analysis methods}

International student mobility (ISM) is a process of movement and choice by international students, involving many factors with multiple impacts on individual students themselves, their families, and communities in both the sending and receiving countries. For the purposes of this paper, the mobility and choice of international students can be observed and analysed using the following elements or dimensions:

The sending country in this paper is both a push factor and a pull factor for ISM. The former is seen in the demand and financial capacity to afford its students to go abroad, while the latter refers to labour market and government policy in attracting and retaining its students graduated from foreign 
universities. By either formal or informal arrangement, the sending country nonetheless influences its diaspora groups in the host country for attracting and supporting its international students.

The host country, as a competitor in the global market, provides a national policy framework in terms of attracting, selecting, hosting and maintaining international students worldwide. In relation to its demographic and labour market conditions, in particular, its migration control policy determines the scope of the choices available to international students between migration and circulation.

Student choice between returning (circulation) or staying (migration) after graduation is related to, or determined by, many factors at different levels from personal preference, career objectives, family livelihoods/migration strategy, and resources at a local level (e.g. internship, work experience) to employment opportunities and constraints at the national level.

Local/diaspora community may influence the flow of ISM and student choices in many ways including, but not limited to, social support (e.g. information, accommodation, ethnic goods such as food and entertainments), employment (both part-time or full-time), and investment (e.g. catering, property, tourism) opportunities. It notes that diaspora community is only part of local communities and in the case of Chinese students, local communities are comprised by Chinese and non-Chinese groups. In addition, it may be the case that different students may give different weight to local communities as whole and to different ethnic groups, leading to different strategies of local engagement among international students.

All of the above elements, however, cannot be separated from the Globalised University, which takes serious steps, measures, and commitments to recruit, maintain and look after international students. The Globalised University aims to meets the needs of international students, by encouraging cross-cultural communication, promoting understanding and sometimes soliciting social support from local and ethnic communities. Bringing the above elements together, a research framework emerges in Figure 1 for the purpose of observing and analysing the mobility and local engagement of Chinese students in destinations. With a focus on local engagement (vertical interaction in Figure 1), a number of hypotheses can be drawn from for the empirical study.

1) Local interconnections influence the choice of Chinese students. This statement suggests that compared to their counterparts who do not have any social contacts with local communities, students who have had such contacts could have not only more opportunities to access to paid or unpaid jobs in local communities but also a greater probability that they will stay in host countries to look for a formal job in labour market after their graduation.

2) Chinese students as a new and emerging group of local communities have had increasingly impact on the development and transformation of local Chinese communities in various aspects from demographic profiles to community organisations.

3) The growth of Chinese students could have positive impacts on the change of landscape of diaspora Chinese communities in the host country. In other words, there is a co-relationship between the growth and distribution between Chinese students and local Chinese residents. 
Figure 1 Mobility and local engagement of international students: An analysis framework

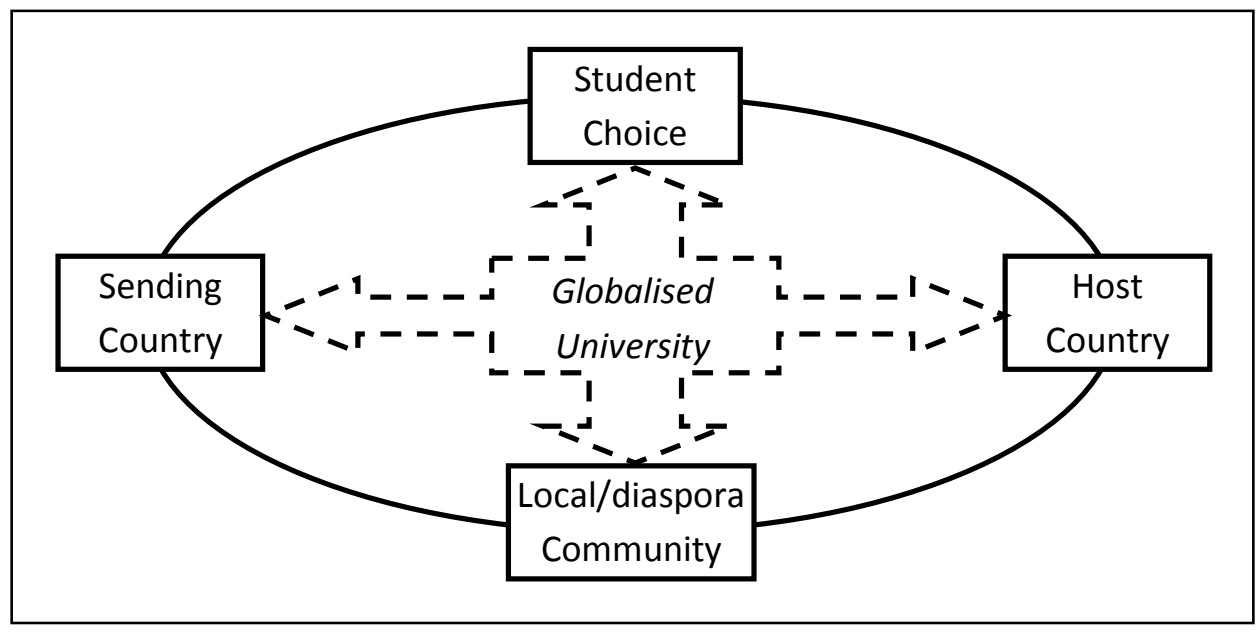

The hypotheses displayed above will be tested via the case of Chinese students and ethnic Chinese groups in England. Alongside the collection of secondary information about the changes of Chinese government policies on Chinese student migration and overseas Chinese communities, two official data sources have been accessed and combined for the purpose of this analysis. One is the UK Census, which contains the distribution information of larger minority ethnic groups including Chinese in 326 districts or boroughs across England in 2001 and 2011 respectively. By bringing the two cohorts of datasets together, the growth and change of distribution patterns between 2001 and 2011 can be identified for the Chinese population, for all ethnic minorities, and for the population as a whole. Another official data source is the quantitative information about the nationalities and source country of international students in all higher education institutes in England. This data is collected and stored in the Higher Education Statistics Agency (HESA). By adding ONS geographic codes into the HEI (HESA) dataset, the number of international students, including Chinese students, can be merged with the ethnic population dataset. This means that the geographic pattern and the statistical correlation between Chinese students and diaspora Chinese population can be analysed and compared at the local authority level ${ }^{1}$.

While the analysis of two official data is to provide a robust statistical test on hypothesis 3 on the correlation between Chinese students and local Chinese residents at macro-level, a questionnaire survey was designed to test hypotheses 1 and 2 in Nottingham, a typical city representing the internationalisation of higher education and Chinese communities across England. With the support of all stakeholders, the survey was conducted in the summer of 2013 which covered all groups, both Chinese students and local residents in Nottingham (Wu, 2013). This survey was also interfaced with a previous survey conducted by Nottingham City Council in 2002 in order to reflect the changes of Nottingham's Chinese community. Concerning the differences between Chinese students and local Chinese residents, two versions of the questionnaire were designed for the two groups respectively.

\footnotetext{
${ }^{1}$ An assumption behind the establishment of the datasets and statistical analyses described above is that university students and in particular those international students live in the same geographic zone as the university at which they study
} 
With an emphasis on the interface with local Chinese residents, nonetheless, the focus of the student questionnaire was on the links, activities, needs and perceptions of the local Chinese community (Wu, 2013: 13).

\section{The background to Chinese student mobility and diaspora Chinese communities since the $1980 \mathrm{~s}$}

The phenomenon of Chinese student mobility in the last decade and their migration choices may not be easily understood unless the history of Chinese student mobility and the evaluation of relevant policies since the 1980s have been taken into account. In relation to the theme of this chapter, particularly, the following factors cannot be ignored: Chinese students/scholars going on global programmes; the development of transnational ties of overseas Chinese communities; and increasing job opportunities within ethnic Chinese labour markets in host countries.

Chinese student mobility and choices between staying and returning migration patterns can hardly be viewed as a new phenomena but can be traced back to the late 1970s when the Chinese government initiated a national programme of Chinese scholars/students going global (Welch and Cai, 2011; Wang and Miao, 2013). In promoting its national strategy of economic development and modernisation, the Chinese government encouraged Chinese students or scholars to go abroad to learn modern science and technology and gain knowledge of advanced management. In addition, they set up a procedure for screening and selecting suitable scholars from universities or national research institutions, and provided funding to sponsor them to go abroad for short-term visiting research cooperation or knowledge transfer. Having adopted a circulation perspective, furthermore, the Chinese government gave freedom to Chinese scholars to decide for themselves whether they wanted to remain abroad to continue their degree studies or to undertake research posts after their short visiting projects. As a result, a large number of Chinese scholars who joined this programme were fortunate enough to gain opportunities to stay and settle down in host countries.

For some, the current wave of Chinese student mobility since the late 1990s can be viewed as a continuity of the early cohort of Chinese scholar mobility in the 1980s and early 1990s. In reality, there are many differences between the two cohorts, including age, work experience, selection process, financial sources, achievements and graduation outcomes. Different from the current student cohort, for instance, almost all of Chinese scholars in the early cohort were leading or established scholars in their universities or research institutes and most of them were selected and sponsored by the Chinese government to take one year visiting research fellowships in foreign universities. Furthermore, a large number of them gained opportunities to continue their degree training courses and became members of academic faculties in universities either in the host or other countries. Despite being a small proportion in terms of the share of diaspora Chinese population, the contribution from those high skilled migrants can never be overestimated for many reasons, including knowledge and familiarity with western higher education systems, social or personal networks with the parents of potential students, as well as professional roles in universities. According to official figures from 1978 to 2012 there was a total of 2.645 million of Chinese scholars and students travelling abroad, of which 90\% were self-funded students (ESL, 2013). By 2012, a total of 1.09 million scholars and students returned to China, and there has been a growing trend of return migration since 2010 (Wang et al., 2013: 171-182). 
Parallel to the outflow of Chinese scholars, there was an effort to reconnect and develop interactions between diaspora Chinese groups and their home communities in China (Qiaoxiang in Chinese). Following the opportunities emerging from the opening of coastal regions and an exportoriented strategy, more and more diaspora Chinese joined the flow of Foreign Direct Investment (FDI) in the 1990s, leading to an increasing demand for qualified managers via the Western higher education system. By 2008, for instance, $63.5 \%$ of FDIs in China were actually owned by overseas Chinese (Liu, 2013: 3). Meanwhile, the Chinese government released the control over population movement both internally and internationally (Pieke and Huang, 2005), which provided new sources for labour supply for diaspora Chinese enterprises. Of equal importance was the development of an international labour brokerage industry (both SOE international contracting labour agencies and private labour brokers for individual overseas employment), which provided important work experience, business networking and even organisational base for international education brokerage later on (Xiang and Shen 2009).

In connection with both China's rise and economic transition, there were increasing opportunities for the development and diversification of ethnic Chinese economies in host countries, leading to various shortages of Chinese labour. Taking the example of Chinese catering - the backbone of Chinese business in the UK - the number of Chinese outlets (restaurants and takeaways) increased from 7,000 in 1981 to 15,000 in 2001 and 17,500 in 2008: an increase of 2.5 times over the period. Comparing the workforce needs for the Chinese catering sector, furthermore, which was estimated at 100,000 in the early 2000s, a labour shortage in excess of 60,000 has been revealed (Lam, 2009). The labour shortage in the UK and other countries has not only led to a rapid growth of low- or unskilled Chinese migrant workers via legal or irregular channels, but also provided part-time work opportunities for many Chinese students. Outside of traditional Chinese businesses, furthermore, we have witnessed the emergence of new businesses for overseas Chinese communities, such as traditional Chinese medicine, international travel and tourism. Employment (either part- or full-time) and business opportunities in both mainstream and local Chinese communities, according to our survey, are important considerations for a large number of Chinese students.

Aside from the traditional destinations of Chinese international migration, of equal importance is the expansion of transnational cooperative networks to new destinations and continents, leading to the establishment and rapid expansion of diaspora Chinese communities world-wide. The celebrated growth of diaspora Chinese population in host countries can be seen from the case of Chinese population in the UK. According to the UK censuses of 2001 and 2011, the Chinese population increased from 154,000 in 1981 to over 400,000 in 2011, an increase of 2.59 times over the period.

\section{Links between Chinese students and local Chinese communities across England}

The links between and contribution of Chinese students to local Chinese communities in the UK can be analysed and compared by looking at the growth and distribution of both Chinese students and diaspora Chinese population. This section attempts to present the results of a statistical analysis based upon the combination of two official datasets described in the previous section.

Based upon information from the Higher Education Statistical Agency (HESA), Table 1 provides an overall picture of the internationalisation of higher education in the UK and the changing position of Chinese students from mainland China since 2000. Three impressive observations can be drawn from Table 1. Firstly, from 2000/01 to 2011/12, the number of Chinese students increased by a 
multiple of 6.9, much higher than the growth rates of international and all UK students, 2.0 and 1.3 times respectively. Secondly, the overall share of international students in the UK HE system has grown significantly from $12.4 \%$ to $19.0 \%$, an increase of $6.6 \%$ in the last 12 years, mainly driven by the growth of non-EU or overseas students whose share of international students increased from $57.5 \%$ to $69.0 \%$, an increase of $11.4 \%$ in the same period. Thirdly, the rapid growth of non-EU students was mainly driven by Chinese students whose share increased from less than $10 \%$ in $2000 / 01$ to more than one quarter (27\%) in 2011/12.

Table 1 Internationalisation of higher education and position of Chinese students in the UK

\begin{tabular}{|c|c|ccc|ccc|}
\hline \multirow{2}{*}{ Year } & All students & International & Non-EU & China & \multicolumn{3}{|c|}{ Share (\%) } \\
\cline { 2 - 8 } & $(1)$ & $(2)$ & $(3)$ & $(4)$ & $(2) /(1)$ & $(3) /(2)$ & $(4) /(3)$ \\
\hline $2000 / 01$ & $1,454,949$ & 180,563 & 103,860 & 9,899 & 12.4 & 57.5 & 9.5 \\
$2001 / 02$ & $1,510,274$ & 190,119 & 118,452 & 16,822 & 12.6 & 62.3 & 14.2 \\
$2002 / 03$ & $1,576,762$ & 214,466 & 144,244 & 29,284 & 13.6 & 67.3 & 20.3 \\
$2003 / 04$ & $1,626,059$ & 231,692 & 162,775 & 39,372 & 14.2 & 70.3 & 24.2 \\
$2004 / 05$ & $1,648,734$ & 244,858 & 167,986 & 42,326 & 14.9 & 68.6 & 25.2 \\
$2005 / 06$ & $1,679,846$ & 251,559 & 170,532 & 40,094 & 15.0 & 67.8 & 23.5 \\
$2006 / 07$ & $1,694,656$ & 266,719 & 180,570 & 38,340 & 15.7 & 67.7 & 21.2 \\
$2007 / 08$ & $1,725,825$ & 280,128 & 188,316 & 38,512 & 16.2 & 67.2 & 20.5 \\
$2008 / 09$ & $1,782,898$ & 303,100 & 206,211 & 40,291 & 17.0 & 68.0 & 19.5 \\
$2009 / 10$ & $1,877,604$ & 333,519 & 228,779 & 48,423 & 17.8 & 68.6 & 21.2 \\
$2010 / 11$ & $1,892,042$ & 351,888 & 243,048 & 58,148 & 18.6 & 69.1 & 23.9 \\
$2011 / 12$ & $1,923,274$ & 364,699 & 251,494 & 68,385 & 19.0 & 69.0 & 27.2 \\
\hline Growth & 1.32 & 2.02 & 2.42 & 6.91 & 6.6 & 11.4 & 17.7 \\
\hline
\end{tabular}

Source: Table created by author based upon the information provided by Higher Education Statistical Agency (HESA). Figures in cells are numbers of full-time equivalent students.

From the perspective of local Chinese communities, however, the term "Chinese students" is not limited to those students from mainland China, but also includes those whose domicile is in Hong Kong, Singapore or Southeast Asian countries or regions with Chinese national identity. In 2011/12, according to HESA, the total of Chinese students by nationality in UK Higher Education Institutions is 73973, of which $90.67 \%$ were from mainland China. For the purpose of this paper, the broader definition of "Chinese students" will be employed.

Based upon the UK Censuses of 2001 and 2011, Table 2 provides an overall picture of the growth and distribution of ethnic groups by region across England. It is notable that the total population of England increased about 9\% during the decade, while the population of minority ethnic groups increased by $73.4 \%$ over the same period. As a result, the share of the latter in the total population has soared from $9.16 \%$ in 2001 to 14.58 in 2011. Similarly, the Chinese population experienced a rapid growth of $72.4 \%$ in the same time period, leading to an increase in its share of the total of population from $0.45 \%$ to $0.72 \%$. Additionally, common to other ethnic groups, Greater London is attractive to the Chinese population, resulting in growth of share of population from $1.1 \%$ to $1.5 \%$, although the contribution of this region to all Chinese populations declined from $36.4 \%$ to $32.7 \%$ during the same period. Aside from Greater London, significant differences can be found between 
Chinese and other minority groups that it is a more balanced distribution of Chinese groups as compared with other groups.

Table 2 Distribution and growth of England population by ethnicity and region (person, \%)

\begin{tabular}{|c|cc|ccc|ccc|}
\hline \multirow{2}{*}{ Region } & \multicolumn{3}{|c|}{ All population } & \multicolumn{3}{|c|}{ Minority ethnicity share } & \multicolumn{3}{c|}{ Share of Chinese } \\
\cline { 2 - 9 } & 2011 & Growth & 2011 & 2001 & Growth & 2011 & 2001 & Growth \\
\hline North East & $2,596,886$ & 3.24 & 4.67 & 2.39 & 102.1 & 0.55 & 0.24 & 136.2 \\
North West & $7,052,177$ & 4.79 & 9.79 & 5.56 & 84.5 & 0.68 & 0.40 & 78.7 \\
Yorks \& Humb. & $5,283,733$ & 6.42 & 11.20 & 6.52 & 82.9 & 0.54 & 0.25 & 130.4 \\
East Midlands & $4,533,222$ & 8.65 & 10.74 & 6.51 & 79.1 & 0.54 & 0.31 & 89.0 \\
West Midlands & $5,601,847$ & 6.35 & 17.28 & 11.26 & 63.3 & 0.56 & 0.31 & 94.3 \\
East England & $5,846,965$ & 8.52 & 9.18 & 4.88 & 104.0 & 0.57 & 0.38 & 64.4 \\
Great London & $8,173,941$ & 13.97 & 40.21 & 28.85 & 58.9 & 1.52 & 1.12 & 54.9 \\
South East & $8,634,750$ & 7.93 & 9.35 & 4.90 & 106.0 & 0.61 & 0.41 & 60.4 \\
South West & $5,288,935$ & 19.41 & 4.59 & 2.44 & 124.2 & 0.42 & 0.28 & 82.5 \\
\hline Total & $53,012,456$ & 8.99 & 14.58 & 9.16 & 73.6 & 0.72 & 0.45 & 72.4 \\
\hline
\end{tabular}

Focusing on the relationship between Chinese students and local Chinese population growth, the distribution of the Chinese population in England is analysed at a local authority level. Table 3 shows that 326 local authority areas (Districts or Boroughs) can be divided into four types according to the ONS coding system: district, unitary, metropolitan district and London Borough. An uneven distribution of HE resources can be seen from the geographic location of HEls, in which 26 out of 201 (or 12.9\%) areas in the "District" category host a university. In other words, 7 out of 8 local authorities in those areas do not have any universities. This is in contrast to Greater London where one in two Boroughs has at least one university. Furthermore, Table 3 shows the differences in terms of mean population by the type of local authority and ethnicity category. Compared with all ethnicity groups, Chinese population share a similar pattern to other minority ethnicity groups (ME) in terms of increasing relative population size from district, unitary, to London Borough. A significant difference between them is the difference in population growth rates: there is no difference for other ethnicity minorities between districts and unitary areas but significant differences are evident for Chinese groups. For the latter, the population growth rate in unitary areas is much higher than that in district areas. One possible explanation is related to the uneven distribution of universities between the two types of areas: the geographic distribution has become an important factor in attracting Chinese student growth and driving the population growth of the local Chinese population. The exception is Greater London where the growth rates of both Chinese and other minority groups are lower due to the larger size in terms of absolute population compared with other local authority areas. 
Table 3 Distribution of England population and HEls by ethnicity and local authority

\begin{tabular}{|c|ccc|ccc|ccc|}
\hline \multirow{2}{*}{ Entity } & \multirow{3}{*}{ No. $\begin{array}{c}\text { University } \\
\text { Presence? }\end{array}$} & \multirow{2}{*}{$\%$} & \multicolumn{3}{|c|}{ Mean $\left(000^{\prime}, 2011\right)$} & \multicolumn{3}{c|}{ Growth (2001-2011,\%) } \\
\cline { 5 - 10 } & & & All & ME & Chinese & All & ME & Chinese \\
\hline District & 201 & 26 & 12.9 & 105.7 & 6.3 & 0.5 & 6.8 & 101.0 & 56.4 \\
Unitary & 56 & 20 & 25.7 & 216.3 & 22.3 & 1.3 & 7.5 & 106.4 & 84.8 \\
Metro. & 36 & 13 & 36.1 & 348.7 & 53.7 & 2.5 & 5.6 & 91.3 & 91.1 \\
London & 33 & 15 & 45.5 & 247.7 & 99.6 & 3.8 & 13.5 & 70.7 & 57.7 \\
\hline Total & 326 & 74 & 22.7 & 162.6 & 23.7 & 1.2 & 7.4 & 97.7 & 65.1 \\
\hline
\end{tabular}

The correlation between the internationalisation of universities and the growth of Chinese population at local authority level, however, need to pass a series of statistical tests. With a contrast between Boroughs with university and those without, for instance, Figure 2 shows a doubling of Chinese population growth rates in all types of local authority areas except London borough areas in which the influence from HE sector looks weak. Compared with the Chinese, the influence of university presence on the growth of other minority groups is also significant but much weaker.

Figure 2Contrast of Chinese population growth rates by geographic division and university presence

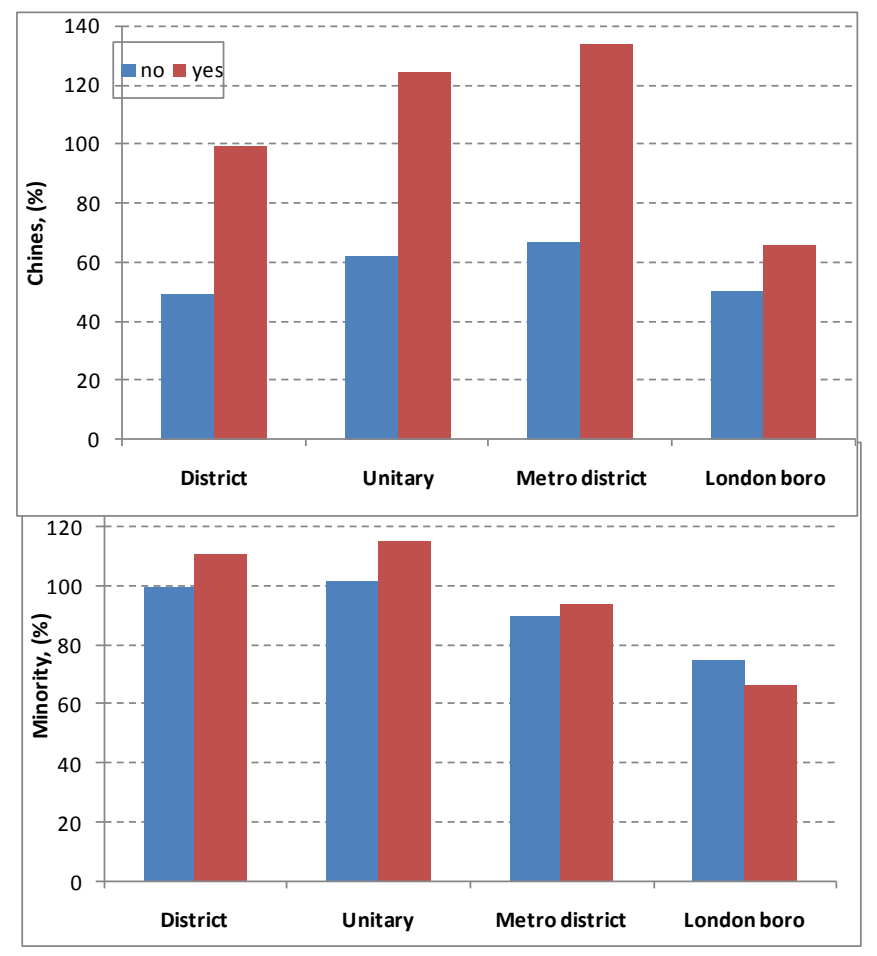

Looking more closely at the relationship between Chinese students and local Chinese population, all local authority areas are further divided into four categories according to the number of universities present: no university, one university only, two universities, and three or more universities. Accordingly, the distribution of 109 areas is displayed in Table 4 in which over three quarters (77\%) of local authorities do not have a university, $15 \%$ have one university only, $5 \%$ have two universities, and only $2 \%$ have three or more universities. In relation to the uneven distribution of university resources, the size of Chinese students increases from less than 450 in one university town or 
districts, 1360 in areas with two universities, to 1705 in areas with three or more universities. In correlation with the size of Chinese students, unsurprisingly, the mean sizes of Chinese populations are about 4000 and 2000 in two and one university areas respectively, more than 6 times and 3 times larger respectively than those without a university. Furthermore, Table 4 confirms the significant impact of university resources on the growth of Chinese population, which is almost double or three times higher than those areas with no universities. The exception is those areas with three or more universities located in London areas, where the distribution and growth of Chinese population may be influenced by other factors.

Table 4 Distribution of Chinese students and Chinese residents byuniversity resources (2011)

\begin{tabular}{|c|cc|cc|cc|}
\hline No. Univ. & No. district & $\%$ & Students & Residents & $\begin{array}{c}\text { Resident growth } \\
(2000-2011, \%)\end{array}$ & $\begin{array}{c}\text { Students in } \\
\text { total (2011, \%) }\end{array}$ \\
\hline 0 & 252 & 77.3 & -- & 636 & 52.7 & - \\
1 & 50 & 15.3 & 448 & 1,968 & 93.2 & 21.2 \\
2 & 17 & 5.2 & 1361 & 4,101 & 147.4 & 29.6 \\
$>=3$ & 7 & 2.1 & 1705 & 6,336 & 87.2 & 27.0 \\
\hline Total & 326 & 100 & 777 & 1,164 & 65.1 & -- \\
\hline
\end{tabular}

Based upon the correlation between Chinese students and the local Chinese population in terms of size and growth rate, Table 4 provides an estimation of the proportion of Chinese students in the total of Chinese population in those university areas. Assuming that no Chinese students attended the UK census 2011, Table 4 shows that the share of Chinese students towards the total local Chinese population varies from $21 \%$ in single university areas to nearly $30 \%$ in areas with two universities.

\section{Local engagement and impact on personal development and local community in Nottingham}

Having examined the relationship of the growth and distribution between Chinese students and local Chinese communities across England, this section aims to reveal the local interconnections of Chinese students and the impacts on their career development and choice between stay and return migration. Empirical evidence will be presented and highlighted based upon a summary of the relevant findings from the survey report (Wu, 2013) and an academic paper (Wu, 2014).

Similar to many middle size cities in England, Chinese community in Nottingham area has also experienced rapid growth. According to the latest UK Census, by 2011 there were 8930 Chinese living in the Nottingham county, of which two thirds lived in the City of Nottingham. The proportion of Chinese in the population of Nottingham County and City was $0.82 \%$ and $1.96 \%$ respectively. Furthermore, compared with 2001 the size of the Chinese population has more than doubled (2.4 times) in Nottingham County and more than tripled in the City of Nottingham (3.5 times). In common with many locations in England, the rapid growth of the Chinese population in Nottingham cannot be separated from the internationalisation of higher education over the last decade. The two universities - the University of Nottingham and Nottingham Trent University - have played a leading role in not only attracting and recruiting Chinese students but also developing and enhancing business links with China, including the establishment of an overseas campus in Ningbo, China, by the University of Nottingham. The number of Chinese students in the two universities, according to 
HESA, has increased eight-fold since 2001 to reach 2819 in 2011. Bringing together two pieces of statistical information, Chinese residents (via the UK Census) and Chinese students (via HESA), it is estimated that the real number of the Chinese population in Nottingham City is likely over 10,000 and the share of students in the Chinese community could be higher than $40 \%$ (Wu, 2013:15).

With respect to changes to Nottingham's Chinese community in the past decade, Table 5 provides a contrast of current survey in 2013 (called "2013 survey" thereafter) and previous survey in 2002 (called "2002 survey"). Of a total of 311 participants in the 2013 survey, 52.1\% (or 162) are students, which is similar to the proportion of students' participation in the 2002 survey. In line with the rapid growth of Chinese immigrants from mainland China, unsurprisingly, $70 \%$ of respondents (both Chinese students and local Chinese residents) came from mainland China, compared with only $40 \%$ in 2002. By the contrast, only $13.4 \%$ of respondents came from Hong Kong in 2013, compared with $40 \%$ in 2002. As we anticipate, there were more young (less than 24 years old) and new immigrants (living less than 10 year in the UK and in Nottingham) in the 2013 survey as compared with the 2002 survey.

Table 5 Comparison of two surveys on Nottingham's Chinese community

\begin{tabular}{lcc}
\hline \multicolumn{1}{c}{ Item } & 2002 survey & 2013 survey \\
\hline Samples: Size & 620 & 311 \\
\hline Students (\%) & $48.1 \%$ & $52.1 \%$ \\
From mainland China & $39.6 \%$ & $70.0 \%$ \\
From Hong Kong & $39.1 \%$ & $13.4 \%$ \\
Female & $51.8 \%$ & $64.3 \%$ \\
Age 18 to 24 & $32.9 \%$ & $44.9 \%$ \\
Living in the city $>10$ yrs & $30.8 \%$ & $14.7 \%$ \\
\hline
\end{tabular}

Source: Wu (2013: 18)

In addition to the change of demographic profiles, another change in Nottingham's Chinese community today is the decline of traditional Chinese community organisations in terms of attracting and influencing new immigrants from China. Taking two major Chinese community organisations, the East England Chinese Association and the Nottinghamshire Chinese Welfare Association as examples, about half of respondents knew them in the 2002 survey, compared with only $20 \%$ in 2013 survey. In contrast to the declining influence of traditional Chinese community organisations, however, our survey shows that there is an increased impact from universities and student organisations. For instance, a large number of respondents ( $50 \%$ and $40 \%$ respectively) recognised the Chinese Students and Scholars Association and the School of Contemporary Chinese Studies, part of the University of Nottingham, which is more than double than those who knew of the traditional community organisations.

Moving on to the social connections of Chinese students outside of university, the survey shows that about $70 \%$ of student respondents claimed that they had such connection while $30 \%$ answered "no". Among those who had links with the wider community, $40 \%$ claim friendship with local Chinese residents with the same identity (e.g. from mainland China), followed by about one third whose friends are non-Chinese, and one in five (21.6\%) have friends in different Chinese group (e.g. from Hong Kong or Singapore). Table 6 confirms that the social networking have had some functions for 
some of Chinese students to gain paid or unpaid job opportunities in local communities. For instance, more than a half of those who have an external relationship in local communities had work experience, which is in contrast to only $17 \%$ in the group who did not have any social contact.

Table 6 Student work experience by social networking with the wider community

\begin{tabular}{|c|cc|c|}
\hline \multirow{2}{*}{ Local networking } & \multicolumn{2}{|c|}{ Working experience } & \multirow{2}{*}{ No. respondents } \\
\cline { 2 - 3 } & No & Yes & \\
\hline No & $83.3 \%$ & $16.7 \%$ & 48 \\
Yes & $47.6 \%$ & $52.4 \%$ & 103 \\
\hline Total & $58.9 \%$ & $41.1 \%$ & 151 \\
\hline
\end{tabular}

Students' work experience, as we assumed, could have a significant influence on their career plan in the near future. For this purpose, students in the questionnaire survey were given five choices about their plans after the end of their current courses. Table 7 shows that for the no-experience group, $44 \%$ of respondents plan on going home, doubling those who have had work experience; while another $31 \%$ considered the possibility of continuing their studies, compared with only $19 \%$ of those with work experience deciding to study further. For the work experience group, the most popular choice is finding a job to stay in the UK. This accounted to $40 \%$, more than triple the no-work-experience group. This seems to suggest that social networking and work experience in particular are important factors in influencing their preference and decision making of whether they would stay in the UK after graduation.

Table 7 Relation between work experience and future plan

\begin{tabular}{|c|ccccc|}
\hline Work exp. & study here & job here & go home & other country & yet decided \\
\hline No & $31.1 \%$ & $12.2 \%$ & $43.3 \%$ & $3.3 \%$ & $10.0 \%$ \\
Yes & $19.0 \%$ & $39.7 \%$ & $22.2 \%$ & $6.3 \%$ & $12.7 \%$ \\
\hline Total & $26.1 \%$ & $23.5 \%$ & $34.6 \%$ & $4.6 \%$ & $11.1 \%$ \\
\hline
\end{tabular}

With respect to the impact of the individual activities on awareness and engagement with the local community, Table 8 shows significant differences of students with local interconnections and those without such connections. Ranked at the top of the list, the Chinese New Year Gala, a unique opportunity which brings together both Chinese, non-Chinese, students and local residents. This event accounts for over two thirds of respondents - including over $40 \%$ of students without local connections. The University of Nottingham Open Day (or May Fest), a platform organised by the university authority for the purpose of promoting and enhancing public participation and local engagement, is known by over $60 \%$ of students with local networks. Taking into account the decline of traditional Chinese community organisations and a lack of freedom in religious practice in mainland China, religious organisations have played an increasingly important role in attracting, facilitating and integrating Chinese students with local communities. In relation to the local Chinese community, unsurprisingly, students with local networks are significantly more aware than their counterparts without the local networks in terms of participating in related events such as Chinese New Year Gala, Chinese community events, and other local social events (e.g. Olympic Torch, New Year Eve celebration). 
Table 8 Contrast of awareness of community events by group (\%)

\begin{tabular}{|l|c|c|c|}
\hline \multirow{2}{*}{\multicolumn{1}{|c|}{ Event }} & \multicolumn{2}{c|}{ Local connection? } & \multirow{2}{*}{ Total } \\
\cline { 2 - 3 } & No & Yes & \\
\hline Chinese New Year Gala & 42.1 & 80.0 & 68.5 \\
\hline Chinese community event & 21.1 & 60.0 & 46.9 \\
\hline Local church activities & 15.8 & 57.8 & 49.4 \\
\hline UoN Community Open Day & 26.3 & 62.2 & 52.5 \\
\hline Local Cultural Festivals & 18.4 & 46.7 & 33.3 \\
\hline Local social events & 21.1 & 60.0 & 45.1 \\
\hline Local sport events & 21.1 & 57.8 & 45.1 \\
\hline Local music event & 18.4 & 46.7 & 45.1 \\
\hline
\end{tabular}

Source: Wu 2014

\section{Discussion and Conclusion}

This paper attempts to drawn attention to the links and impacts of Chinese student mobility in diaspora Chinese communities in destinations. Central focus is paid to whether or how local engagement of Chinese students influence the development of both sides. An analysis framework and research hypotheses are posed for collecting official data across England, and designing a questionnaire survey in Nottingham Chinese community. Based upon the analysis and presentation of official and surveyed data, a number of research findings and conclusions are drawn as follows.

Firstly, of many factors influencing Chinese student mobility, the roles of local communities in attracting, facilitating and supporting Chinese students cannot be ignored. In this regard, the simultaneous growth of Chinese international students and ethnic Chinese population in the UK in the first decade of the $21^{\text {st }}$ century seems to suggest that Chinese students are not "parallel" or totally separate from, but have become an important part of diaspora Chinese communities. If this is true, it is reasonable to assume that the large scale and unprecedented growth of Chinese students has provided a new momentum for the development and expansion of diaspora Chinese communities in the UK and other major higher education provision countries. Such assumption has been confirmed by a recent report published by Migration Policy Centre of European University Institute (Unterriner 2015: 12). Among those born in mainland China who registered in the UK census in 2011, according to the above report, since 2001 three quarters were new migrants due "mainly to student migration".

Secondly, the correlation of the growth and distribution between Chinese international students and Chinese resident population at the local level has been confirmed by our statistical analysis. By bringing together two official datasets, UK censuses and HESA international student information at local authority areas, this paper has shown that the growth rate of local Chinese population in those university base towns or cities in the first decade is at least twice higher than those without any universities, which is quite different from the patterns of any other international students whose impacts on the growth of BME population were not significant. The exception is big cities such as London, Birmingham and Manchester where there are more than three universities and where the impact of Chinese student mobility is only one of many factors influencing the growth of local Chinese population. 
Thirdly, Chinese student mobility and impact on diaspora Chinese communities in destinations cannot be fully understood unless the interconnections between Chinese students and local communities including diaspora Chinese communities have been taken into account. For this purpose, a questionnaire survey was designed and conducted in Nottingham's Chinese community to identify changes in the local Chinese community in the past decade and in relation to Chinese students, and to reveal the existence of local engagement and the contribution to the development of both Chinese students and local Chinese community. The survey has shown not only that the rapid growth of local Chinese resident population was driven by the growth of Chinese students, but also the on-going transformation of local Chinese community in terms of demographic profiles and community organisations towards increasing influences of universities and student associations.

Fourthly, the key finding of this paper is the existence and functions of local engagement, defined as interconnections and interactions of Chinese students with the wider community, both Chinese and non-Chinese groups outside universities. The survey shows that not all but $70 \%$ of student respondents claimed that they have established and maintained social contacts with local people with varying degrees and for various purposes. Furthermore, social networking with local communities, is significantly related to Chinese student's personal experience in the access to paid or unpaid jobs during their study and their subsequent career developments after graduation. The above results have confirmed that not only could local engagement help Chinese students to develop their local knowledge, intercultural competences and work experience, but also influence their choice and decision making of their migration or circulation. Nonetheless, the variety of attitudes or experiences of local engagement in destination is also an important factor or cause for the diverse discourses among Chinese students in terms of professional quality and career development, which is often ignored by international higher education scholars.

Finally, not limited to the personal development and migration decision, the local engagement offers an important channel for Chinese students to participate in and contribute to the development of local Chinese community towards the community cohesion and integration. Taking into account the segmentation and fragmentation of diaspora Chinese communities (Benton and Gomez, 2011; 2014), whether or to what extent Chinese students can be accounted as a part of diaspora Chinese communities is crucial for the development of diaspora Chinese studies in the era of globalisation of higher education $(\mathrm{Wu}, 2016)$. The correlation between students' awareness of local community events and their social networks seems to suggest the potential of "local engagement" for further inquiring and understanding of the role of Chinese student mobility in the transformation of diaspora Chinese communities. Nonetheless, this chapter sheds new light on the co-development of Chinese international students and diaspora Chinese communities, to which further empirical research are needed. 


\section{References}

Benton, G, and Gomez, ET. 2011. The Chinese in Brittain, 1800-present economy, transnationalism, identity, Hamphshire and New York: Palgrave Macmillan.

Benton, G, and Gomez, ET. 2014. Belonging to the nation: generational change, identity and the Chinese diaspora, Ethnic and Racial Studies, 37(7), 1157-1171.

Bhagwati J. 1976. The Brain Drain and Taxation, Theory and Empirical Analysis.North-Holland: Amsterdam.

Bourdieu P. 1986.The forms of capital. In Handbook of Theory and Research for the Sociology of Education, Richardson JG (ed.). Greenwood Press: New York; 241-258.

Brickell K, and Datta, A (eds.). 2011. Translocal Geographic Spaces, Places, Connections. Ashgate: Aldershot.

Business, Innovation and Skills (BIS). 2013. International Education: Global Growth and Prosperity, London: The Department of Business, Innovation and Skills. Online at: http://www.gov.uk/bis, latest accessed on 25 November 2013.

Collins FL. 2009. Connecting 'home' with 'here': personal homepages in everyday transnational lives. Journal of Ethnic and Migration Studies 35: 835-859.

De Wit H, Agarwal P, Said ME, Seehole MT, Sirozi M (eds). 2008. The Dynamics of International Student Circulation in a Global Context. Sense Publishers: Rotterdam.

Education Online (EOL). 2011. Report for Chinese students going abroad (2011), in Chinese, online at http://liuxue.eol.cn/html//xrep/index.shtml\#c01s11, accessed on 26 August 2013.

Figueroa FE. 2010. The Bologna Process as a hegemonic tool of Normative Power Europe (NPE): the case of Chilean and Mexican higher education. Globalisation, Societies and Education 8: 247-256

Findlay, AM. 2011. An assessment of supply and demand-side theorisations of international student mobility. International Migration, 49(2): 162-190.

Gargano T. 2009. (Re)conceptualizing international student mobility: the potential of transnational social fields. Journal of Studies in International Education, 13: 331-346.

Geddie K. 2013. The transnational ties that bind: relationship considerations for graduating international science and engineering research students. Population, Space and Place, 19(2): 196-208.

Guarnizo, LE. 2002. The economics of transnational living, International Migration Review, 36: 666699.

Kell $\mathrm{P}$ and Vogl G (eds). 2008a. Perspective on mobility, migration and the well-being of international students in Asia Pacific, International Journal of Asia Pacific Studies, 4(1): 5-18.

Kell P and Vogl G (eds). 2008b. Transnational Education: The politics of mobility, migration and the well-being of international students, International Journal of Asia Pacific Studies, 4(1): 21-31.

King, R. and Raghuram, P. 2013. International student migration: mapping the field and new research agendas. Population, Space and Place, 19(2): 127-137.

Kramer P. 2009. Is the world our campus? International students and U.S. global power in the long twentieth century. Diplomatic History 33: 775-806.

Liu, H. 2013. Conceptualization and Practices of Transnational Asia: China Model, Ethnic Networks and International Relations, Nanjing: Nanjing University Press (in Chinese).

Lam, J. 2009. Labour shortage in Chinese catering, a presentation to The University of NottinghamInternational Labour Organisation Workshop, Employment of Chinese Migrant Workers in UK: Issues and Solutions, 22-23 October 2009, Nottingham, online at:

http://www.nottingham.ac.uk/cpi/documents/funded-projects/ilo-workshop-complete-report.pdf 
Merrick, B. 2013."Whose initiative? International student policy in the UK", in Sovic and Blythman (eds), International Students Negotiating Higher Education: Critical perspectives, London and New York: Routledge, pp. 28-38.

Mosneaga A, Winther L. 2013. Emerging talents? International students before and after their career start in Denmark. Population, Space and Place, 19(2): 181-195.

Neilson, B. 2009. The world seen from a taxi: students-migrants-workers in the global multiplication of labour. Subjectivity, 29: 425-444.

Office of National Statistics (ONS), 2012. Changing of ethnicity over time, http://www.ons.gov.uk/ons/rel/census/2011-census/key-statistics-for-local-authorities-in-england-andwales/rpt-ethnicity.html\#tab-Changing-picture-of-ethnicity-over-time; the latest access on 25 November 2013.

Raghuram P. 2013.Theorising the spaces of student migration. Population, Space and Place, 19(2): $138-154$.

Robertson S. 2010. Globalising UK Higher Education. Centre for Learning and Life, Chances in Knowledge Economies and Societies: London.

Robertson S. 2011. Student switchers and the regulation of residency: the interface of the individual and Australia's immigration regime. Population, Space and Place, 17(1): 103-115.

Saxenian, AL, 2005. From brain drain to brain circulation: Transnational communities and regional upgrading in India and China, Studies in Comparative International Development, 40(2):35-61.

Shen, W. 2009. Chinese Student Circular Migration and Global City Formation: a Relational Case Study of Shanghai and Paris. Unpublished PhD thesis, Loughborough University.

Sovic, S. and Blythman, M (eds). 2013. International Students Negotiating Higher Education: Critical perspectives, London and New York: Routledge.

Xiang, B and Shen W. 2009.International migration and social stratification in China. Journal of Educational development 29: 513-522.

Wang, HY and Miao, L. 2013. Annual Report on the Development of Chinese Students Studying Abroad (2013) No.2, Beijing: Social Sciences Academic Press (in Chinese).

Wang, HY; Miao, L. and Zheng, JL. 2013. Reflection on China's cultivation of international talents against the backdrop of the "overseas study deficit", in Wang and Miao (eds), Annual Report on the Development of Chinese Students Studying Abroad (2013) No.2, Beijing: Social Sciences Academic Press (in Chinese), 171-182.

Waters, JL. 2006. Geographies of capital: education, international migration and family strategies between Hong Kong and Canada. Transactions of the Institute of British Geographers, 31: 179-92.

Waters J, Leung M. 2013. Colourful university life? Transnational higher education and the spatial dimensions of institutional social capital in Hong Kong. Population, Space and Place, 19(2): 155-167.

Welch, A. and Cai, HX. 2011. Enter the Dragon: The internationalisation of China's higher system, in Ryan, J. (ed.), China's higher education reform and internationalisation, London and York: Routledge, pp. 9-33

Wiers-Jenssen J. 2008. Does higher education attained abroad lead to international jobs? Journal of Studies in International Education, 12: 101-130.

Wu, B. 2013.Nottingham Chinese Community in Transition: A survey report of community cohesion, integration and university engagement, Nottingham: Centre for Chinese Migration Studies, University of Nottingham.

Wu, B. 2014.Chinese student migration and integration in the UK: An exploration of links to and engagement with local communities in Nottingham"; COMPAS Working Paper, No. 118, University of Oxford, 2014; online: 
http://www.compas.ox.ac.uk/fileadmin/files/Publications/working_papers/WP_2014/WP14118_Chine se_Students_Integration_final_BW_1_June_2014.pdf

Wu, B. 2016.Chinese student diaspora, social networking and local engagement in England: An empirical study, Journal of Chinese Overseas, forthcoming

Unterreiner, Anne (2015) The immigration, emigration and diaspora policies' effects on integration:

Chinese and Indian Migrants in the UK, INTERACT Research Report (Corridor Report on the United

Kingdom), Migration Policy Centre, European University Institute.

http://cadmus.eui.eu/bitstream/handle/1814/34683/INTERACT-RR-2015\%20-

\%2005.pdf?sequence=1, accessed on 20 March 2015. 